\title{
Congenital Pseudarthrosis of the Tibia: Combined Pharmacologic and Surgical Treatment Using Biphosphonate Intravenous Infusion and Bone Morphogenic Protein with Periosteal and Cancellous Autogenous Bone Grafting, Tibio-Fibular Cross Union, Intramedullary Rodding and External Fixation
}

\author{
Dror Paley \\ Paley Institute,
}

St. Mary's Hospital, West Palm Beach, Florida,

USA

\section{Introduction}

Congenital pseudarthrosis of the tibia (CPT) is one of the most challenging problems confronting pediatric orthopedic surgery. Fifty percent of cases are associated with neurofibromatosis, ten percent with fibrous dysplasia or Campanacci's osteofibrous dysplasia and forty percent are idiopathic. CPT has a tendency to refracture until skeletal maturity. Fractures can even occur in adults. The refracture incidence is reversely proportional to age. Consequently success rate of treatment methods is also age dependent and directly proportional to age. This may be related to the activity of the pathologic tissue being greater at a younger age when growth rate and metabolism are at their greatest. It may also be a function of the diameter of the bone which is smaller at a younger age and therefore more prone to fracture.

Various techniques for the management of CPT have been described. McFarland [32] described a bypass fibular graft, Boyd [3] and Boyd and Sage [4] described a double onlay graft taken from the opposite tibia combined with autologous iliac crest graft, Charnley [6] described intramedullary (IM) rods, and Sofield [41] added fragmentation and reversal of fragments. Campanacci and Zanoli [5] described a "fibula pro tibia" technique with fibular fixation to the pseudarthrosis site. Other methods include direct current or pulsed electromagnetic field, ipsilateral transfer of the fibula or contralateral free vascularized fibular transfer, circular external fixation, IM rodding, and combined external fixation and IM rodding. More recently, bone morphogenic protein (BMP) [28] and bisphosphonate therapy $[20,39]$ have been used. The results of all these methods have been variable. Refracture rates are high with all of these methods. 


\subsection{Pathology of CPT}

The pathology of CPT is still unknown. During the past 100 years, a number of theories have been suggested to explain the development of the disease. Today, interest concentrates mainly on the pathologic changes of the periosteum [19]. Codivilla [8] was the first to implicate the periosteum in the pathology of CPT.

McElvenny [31] reported a markedly thickened, closely attached periosteum that caused constriction of the bone with subsequent atrophy and pseudarthrosis. The findings presented by McElvenny were echoed by Boyd [3] and Boyd and Sage [4], who suggested that CPT was caused by aggressive osteolytic fibromatosis and that those findings had been confirmed by specimens of amputated legs. Blauth et al. [1] reported the findings of a pathologic study of 10 patients with CPT and postulated that the thickened periosteum might be caused by myofibroblast overgrowth [21]. A more recent report [19] suggested that the thickened periosteum was caused by neural like cells that form a tight sheath around the small periosteal vessels causing narrowing or obliteration of vessels This results in disturbance of the blood circulation of the periosteum, which in turn results in impaired oxygen and nutrient supply of the subperiosteal bone with subsequent fracture and recalcitrant nonunion.

Cho et al. [7] studied osteoclastic and osteoblastic activities of the periosteum of seven patients with CPT compared with those of two controls. They concluded that periosteal cells stay in undifferentiated form rather than growing into abnormal cells with variable responses to BMP-2. The osteoclastic activity of the periosteum was significantly higher than that of the control, and the authors postulated that not only pathogensis of CPT but also refracture after initial healing and resorption of bone grafting are related to osteoclastic activity of the periosteum. They concluded that while the fibrous hamartoma maintains some of the mesenchymal cell phenotypes they do not undergo differentiation in response to BMP. They also showed that these cells were also more osteoclastogenic than normal tibial periosteal cells.

Schindeler et al, showed that NF1(+/-) mouse cells exhibited less osteogenic potential than $\mathrm{NF} 1(+/+)$ cells (controls). In response to BMP the former revealed significantly less bone formation than the latter although BMP did stimulate bone formation in a heterotopic bone formation model. Co-treatment with zolidronic acid (ZA) lead to synergistic increase in bone formation in both groups. They concluded that biphosphonate-BMP combination therapy was superior to BMP therapy alone.

\subsection{Periosteal grafting}

Resection of hamartomatous fibrous tissue is part of many treatment protocols, but it does not ensure healing or prevent refracture. Codivilla recommended osteo-periosteal grafting more than 100 years ago [8]. Cambras (circa 1977, personal communication 1996) treated CPT with bone and periosteal grafting from the child's mother, emphasizing the role of the periosteum to cure the disease. Paley [13] proposed periosteal grafting as a treatment option in 1995 based on observations he made during his first 8 years of treating this condition [37]. Paley's periosteal grafting method was first published in a doctoral thesis by El Rossasy [14] in Egypt in 2001 and then in a book edited by Rozbruch in 2007 [13]. Paley's periosteal 
grafting method was used and reported on by Michael Weber [44] from Germany and Franz Grill from Austria [IPOS meeting 2006, Orlando, Florida]. A two center study combining the experience with periosteal grafting from Paley and Kocaoglu was published in 2008 by Thabet et al [42].

The Paley method of periosteal grafting described by Thabet et al was the culmination of twenty years of experience in the treatment of CPT. Paley's first report was in 1992. Followup of those and additional early Paley treated patients reported in El Rossasy's doctorate thesis demonstrated a high refracture and retreatment rate. The initial treatment was using the Ilizarov method with bone grafting of the CPT site combined with hamartoma resection. The healing rate was nearly $100 \%$ but the refracture rate was over $50 \%$. When an IM rod was added to the Ilizarov-bone grafting treatment the refracture rate drastically dropped. Clearly the Ilizarov fixation method was excellent at obtaining union but failed to maintain union. The IM rod was excellent at maintaining union and decreasing refracture. This was also the conclusion of the multicenter EPOS study by Grill et al [17]. The efficacy of the IM rod was also increased by rodding both bones in the leg rather than just one.

Based both on the literature and on his own experience the other two factors that significantly helped decrease refracture were increasing the cross sectional area of union and eliminating angulation especially at the CPT site. Combining all of these principles Paley proposed the treatment method that was studied in the two center study reported in Thabet et al [42].

\section{Paley combined pharmacologic and surgical method of treatment of CPT}

Based on the new information from the recent patho-etiologic studies, Paley combined his periosteal grafting methodology [Thabet et al] with pharmacologic treatment using BMP and bisphosphonate infusion. This combination has reduced the refracture rate and accelerated the union rate as never previously observed or reported. While the union rate published in Thabet et al [42] was 100\% there was a 40\% refracture rate. All of these united when retreated with BMP and ZA infusion. Since the study in the 2008 publication Paley treated 15 additional cases of CPT. All united in 3-4 months and none have refractured with an average followup on average of 2 years (range 1-4 years). In addition to the previous method three changes were made to the original treatment methodology: 1) a cross union was created between the tibia and the fibula; 2) BMP was applied between the cancellous bone graft and the soft tissues as a surrounding layer including between the tibia and fibula; 3) Zolidronic acid infusion was given with the index procedure and at the time of removal of the external fixation.

\subsection{Paley pharmacologic and surgical technique protocol (Fig 1)}

Pharmacologic: Biphosphonate Infusion: One week prior or one week after the surgery the patient is given a Zolidronic Acid infusion intravenously $(0.2 \mathrm{mg} / \mathrm{kg})$ over 30 minutes. One hour later calcium gluconate $60 \mathrm{mg} / \mathrm{kg}$ is given intravenously over the course of one hour. The patient is given $2 \mathrm{gm}$ elemental calcium for 7 days and Vitamin D supplementation of $400 \mathrm{IU}$ for 14 days. Bone morphogenic protein which according to the FDA is considered an implant is nevertheless a protein and a growth factor. I therefore refer to its use herein as pharmacologic. Since it is applied in surgery it will be referred to there. 
Surgery: The patient is placed supine, with a bump under the ipsilateral buttock, on a radiolucent table. The entire lower extremity and hemipelvis are prepped and draped free. The leg is exsanguinated and tourniquet applied. The pseudarthrosis site is approached through an anterior longitudinal incision. The thick periosteum is incised longitudinally. The periosteal incision ends at the point at which the periosteum thins to a normal thickness. Dissection between the periosteum and the surrounding soft tissues is carried out circumferentially around the tibia. Avoid injury to the anterior tibial artery laterally and the posterior tibial neurovascular bundle posterormedially.

After the hamartomatous periosteum is excised circumferentially, the proximal segment of the tibia is split by using a fine saw (Fig. 1). The split is created in such a way that it does not fracture either arm of the split. The tibia resembles the old-fashioned one-piece wooden clothes pins. The fibular pseudarthrosis is approached by dissecting posterolateral to the tibia. The fibular periosteal hamartoma is also resected.

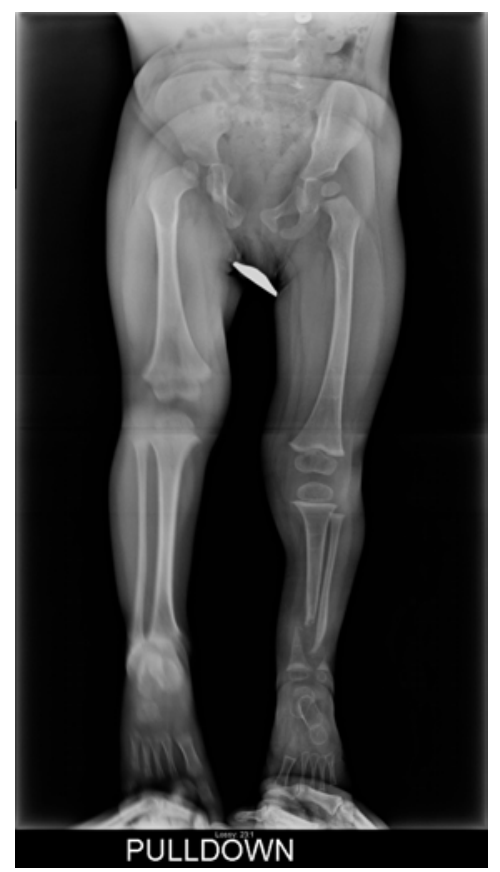

Fig. 1a. Long AP radiograph of 16 month old girl with NF and CPT left tibia with a LLD.

The distal tibial medullary canal is drilled open. The end of the distal tibia is inserted into the split of the proximal segment (occasionally when the CPT is in the mid-diaphysis instead of distal third the distal fragment is split the proximal is invanginated into the distal split). The proximal fibula is invaginated into a similar split of the distal fibula. The tibia and fibula are shortened by 1 to $2 \mathrm{~cm}$. In a previously unoperated case, the only bone resection that is performed is the minimal required to open the medullary canal. In a previously operated case there may be dead bone present which should be resected. To determine what bone is alive vs dead, the tourniquet is released and all non bleeding bone is resected. A high speed burr is helpful in causing the bone to bleed while doing controlled debridement. 
Congenital Pseudarthrosis of the Tibia: Combined Pharmacologic and Surgical

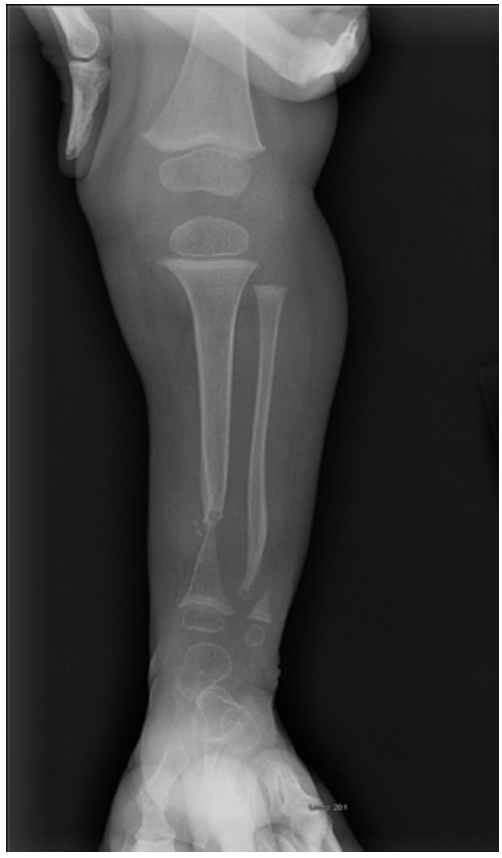

Fig. 1b. AP of the tibia before surgery.

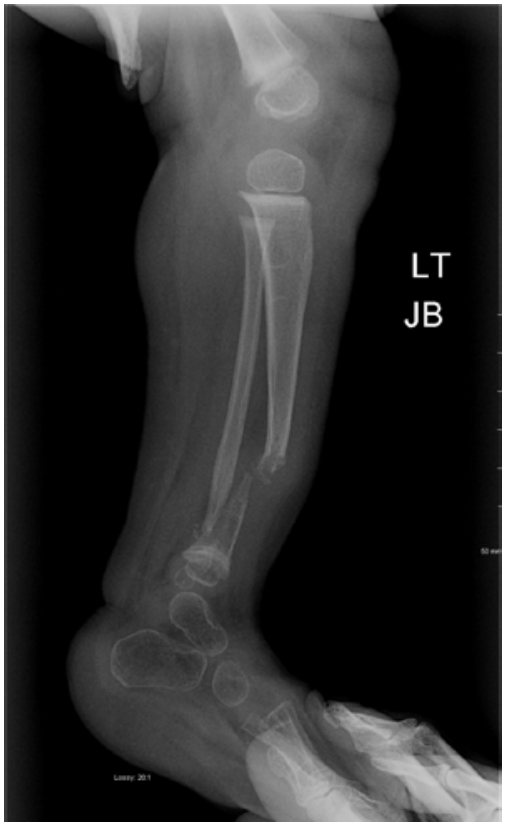

Fig. 1c.Lateral of the tibia before surgery. 


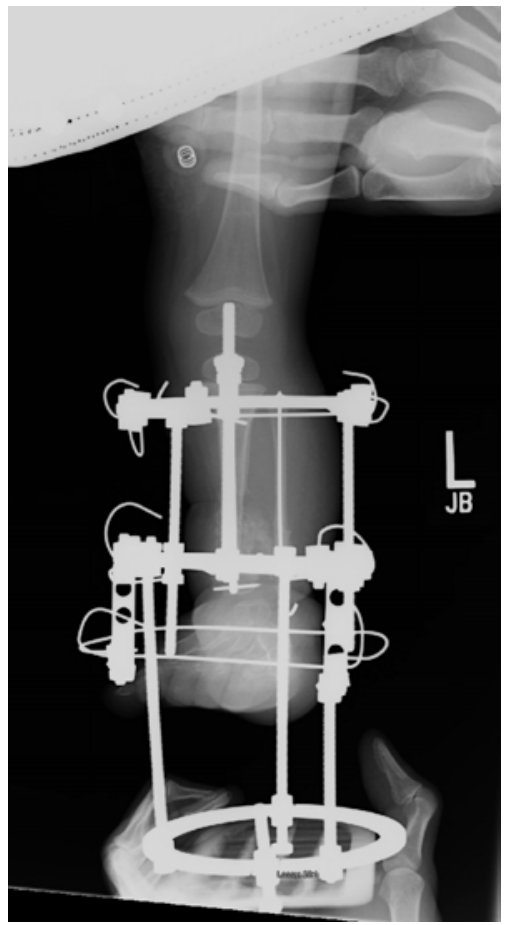

Fig. 1d. AP of the tibia after surgery with telescopic IM rod in place and Ilizarov device in place. Note the walking extension on the external fixator that allows for equalization of the leg length and weightbearing during treatment.

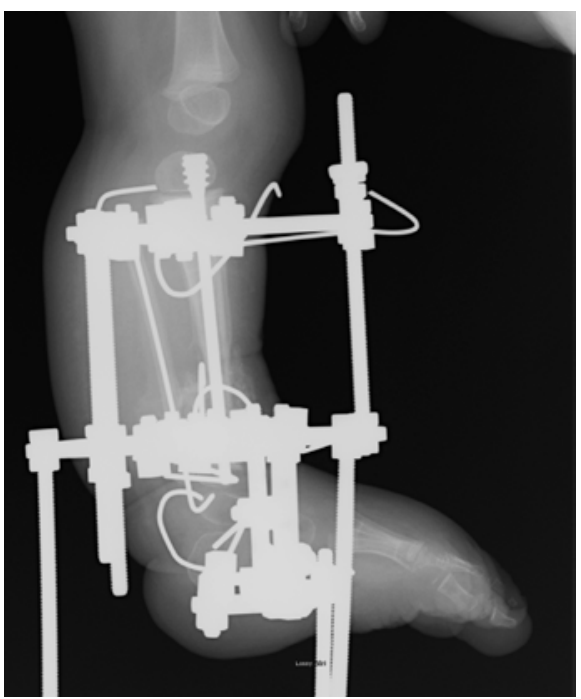

Fig. 1e. Lateral of the tibia after surgery. 


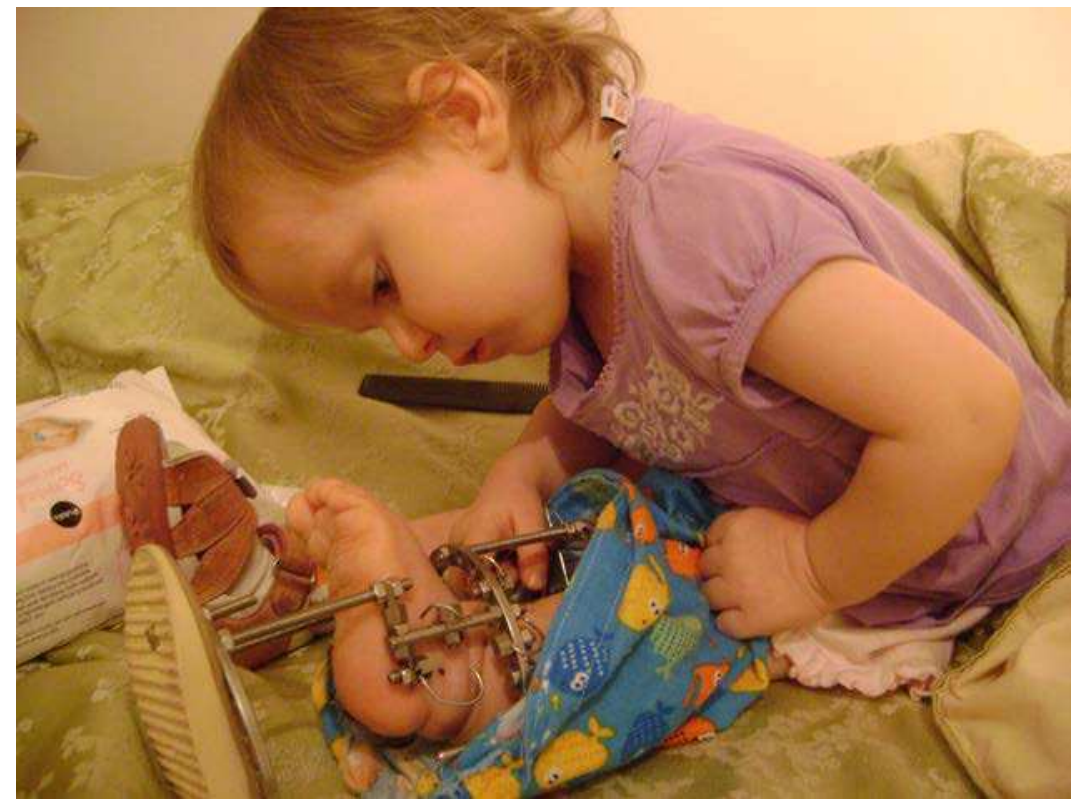

Fig. 1f. Photograph of the child with the external fixator on. She had little pain and few pin site problems.

An IM rod is inserted across the CPT site. The implant used depends on the age and diameter of the CPT bone. One can use a Kirschner wire or Steinmann pin in very-smalldiameter bone or a Rush rod or flexible titanium rod in larger diameter bones. The rod can be inserted from distal to proximal via the medial malleolus or from proximal to distal crossing the proximal physis. The distal to proximal technique is much more difficult because the medial malleolus is very medially located relative to the mid-diaphyseal line. There is a tendency to create a lateral translation deformity if the rod is not properly molded. Most recently, we have used the Paley-modified Fassier-Duval telescopic IM nail system (Pega Medical, Inc. Laval, Quebec, Canada) from proximal to distal. The Paley modification of this nail allows locking into the distal tibial epiphysis using a threaded $1.6 \mathrm{~mm}$ Kirschner wire. It is preferable to avoid rodding across the ankle joint to prevent stiffness of the ankle joint and permanent poor push-off strength [23]. The fibula should be rodded retrograde from the lateral malleolus using a wire of between $1-2 \mathrm{~mm}$ in diameter. It is important to coordinate the rodding and shortening of the tibia and fibula so that one bone does not impede the shortening of the other bone.

An incision is then made along the iliac crest. The apophysis is split and the medial periosteum with the iliacus muscle reflected medially off the ilium. The cancellous bone between the cortical tables of the ilium is harvested. In young children this will not yield enough bone. Therefore the tables can be split with a sharp osteotome towards the roof of the acetabulum. There is a large amount of cancellous bone located in the supra-acetabular region. This can be reached with a curette after splitting the tables using image intensifier guidance. Even in a one year old child there is ample cancellous bone to be found in the supra-acetabular region. The bone in the donor site reconstitutes after the harvest. 


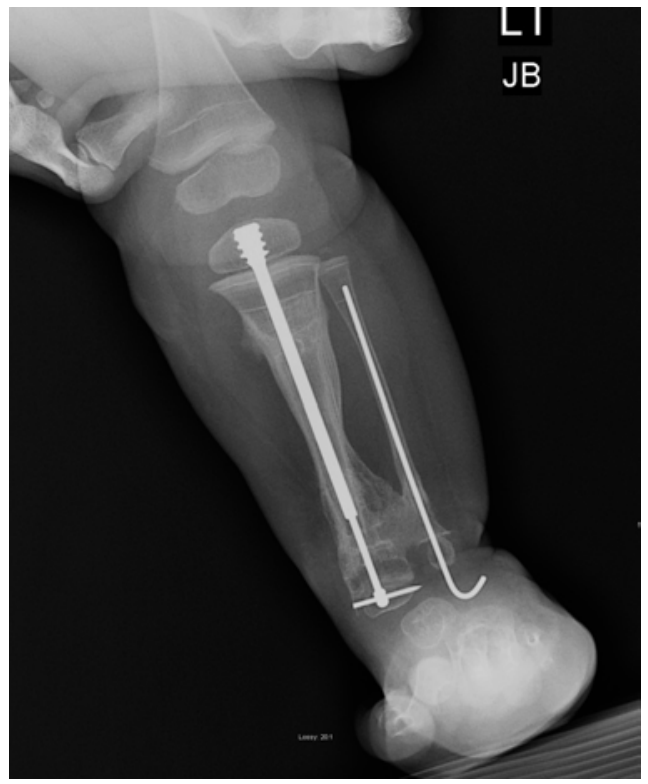

Fig. 1g. Long AP radiograph standing showing the remaining LLD that will be treated at a later date. The tibia and fibular are healed.

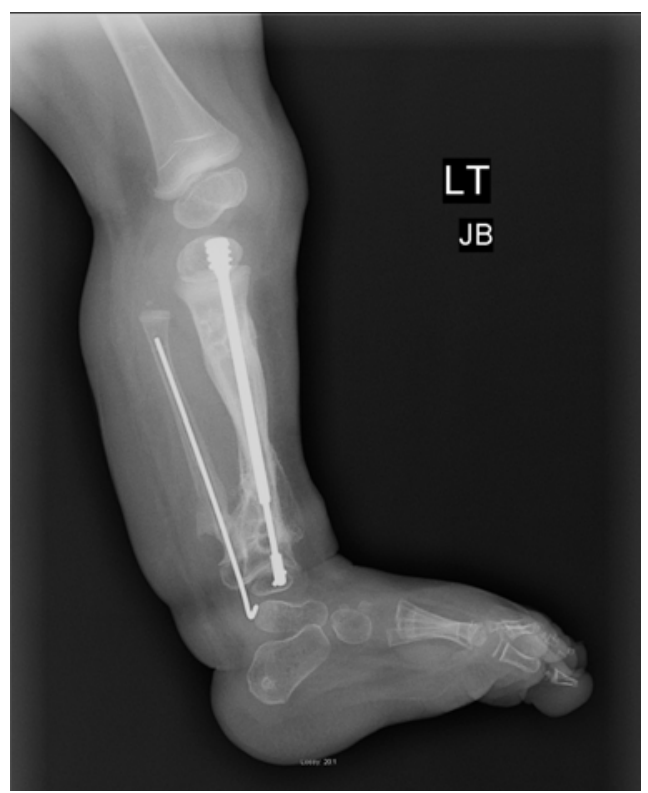

Fig. 1h. AP radiograph of the tibia showing the Fassier-Duval with the distal Paley modificaiton (locking to the distal epiphysis with a threaded k-wire). The tibia and fibula show a cross union and both bones show are now solidly united. 
The best place to procure periosteum is beneath the iliacus muscle. If more is needed then the periosteum beneath the gluteal muscles can also be harvested by reflecting the lateral half of the apophysis off of the lateral table of the ilium. A knife is used to incise the periosteum in as long and as wide a rectangular piece as possible. The periosteum is then separated from the overlying muscle. The periosteum immediately shrinks to a quarter its original size. To restore some of its size, it is placed through the skin graft mesher and expanded. The meshed periosteum is expanded and then wrapped around the invaginated bone ends of the pseudarthrosis site. It is important that the cambium layer face the bone. To apply the periosteum two sutures can be tied to two of the corners of the rectangular graft. The graft is then pulled around the posterior aspect of the bone and sutured to itself. The same is done to the fibular pseudarthrosis site. The cancellous bone graft is then placed circumferentially around the pseudarthrosis site and filled into the space between the two bones. Finally bone morphogenic protein (BMP-2; Infuse, Medtronics, Memphis, TN) is placed around the bone graft between the bone graft and the surrounding soft tissues. The bone grafting and BMP are especially located in the space between the tibia and fibula to create a cross union. The wound is then closed over a Hemovac drain.

After closure, an Ilizarov all-wire frame is applied to the limb. This requires three wires in the proximal metaphysis (two counter opposed olive wires and one smooth wire), three distal wires, and foot fixation. The wires should not be in contact with the IM rod. A walking ring is applied postoperatively so that the patient does not have to bear weight on the foot. The main purpose of the fixator is to give rotatory control and stability to the pseudarthrosis site.

\section{Post-operative management}

The patient's wound is checked two weeks after surgery. Radiographs are obtained at 6 and 12 weeks after surgery. The bone is usually united by 12 weeks after surgery. The external fixator can be removed once radiographic union is confirmed and a long leg walking cast applied. After removal and after the swelling decreases the patient should be measured for a knee-ankle-foot orthotic with a free knee hinge and a solid ankle. As the patient grows the brace should be remade. Eventually (over age 6), an articulated ankle is added. As the patient gets older the length of the brace is reduced. Then the thigh cuff is removed and only a total contact articulated AFO or PTB brace used. When the patient is older (over age 10 a gator brace (no foot part with lateral and medial malleolar flanges) is used. Brace wear at all times including during sleep and swimming is used until skeletal maturity. The only time the brace is taken off is for bathing and for physical therapy. Sports and other activities are allowed while wearing the brace. Patients treated engaged in wrestling, surfing, skiing, cycling, etc.

The IM rod should be changed as needed. If a telescopic rod is used it should be changed to a larger diameter rod as the patient grows. Since the length of the bone doubles from age 3 in girls and 4 years old in boys till skeletal maturity, the telescopic rod has to be changed once before maturity and once before age 4 . Zolidronic acid infusion should be given with each rodding surgery.

Hemiepiphysiodesis is also performed if a valgus ankle or knee is present. The presence of the rod does not impede the use of a hemi-epiphysiodesis screw plate device. 


\section{Discussion}

The natural history of CPT is recalcitrant nonunion, atrophy of the bone and the leg, progressive LLD and deformity, and recurrent refracture even after union is acheived in surgery $[3,4,22,29,33]$. The primary objective of treatment for CPT is to obtain union. The secondary objective is to maintain union. In addition, many associated deformities of length and angulation should be addressed in the comprehensive management of CPT. Therefore, unless all patients have reached skeletal maturity, the refracture rate reported is always lower than actual [3, 4, 33].

The main surgical options for treatment of CPT are vascularized fibular grafting, IM stabilization, external fixation with a circular frame, and amputation [9-11, 17, 18, 26, 30, 35]. Electric stimulation has also been studied $[37,38]$

Paley et al. [35] presented a report of 15 patients who had 16 tibiae with congenital pseudarthrosis. The mean patient age was 8 years, the rate of union was $94 \%$ in 15 patients with Ilizarov frames, refracture occurred in five tibiae $(31 \%)$, and the mean followup duration was 4 years.

Boero et al. [2] presented a report of 21 patients with neurofibromatosis treated with Ilizarov frames. The mean patient age was 8.8 years. The primary union rate was achieved in 17 of 21 $(81 \%)$ patients. Refracture occurred in four of the 17 patients $(19 \%)$, and the minimum followup duration was 2 years.

The European Paediatric Orthopaedic Society (EPOS) multicenter study [17] of 340 patients with $\mathrm{CPT}$ reported a $75 \%$ healing rate achieved with Ilizarov external fixation and recommended the use of prophylactic IM rodding to prevent refracture.

In a series of 17 tibiae with CPT treated by Paley and Herzenberg, half of which were followed up to skeletal maturity, the mean patient age was 8 years, union was obtained in $100 \%$ of the patients, and refracture occurred in $68 \%$ when the Ilizarov device without IM rodding was used [14]. When IM rodding was combined with external fixation, the refracture rate dropped to $29 \%$.

Ohnishi et al. [34] reported 73 cases that were treated with different treatment protocols: 26 with Ilizarov fixation, 25 with vascularized fibular grafting, seven with the combination of the previous two techniques, six with IM rodding combined with free bone grafting, five with plating and grafting, and the remaining four with different treatment protocols. The average patient age was 5 years. Union was achieved in all patients treated with Ilizarov fixation (four experienced refracture), 22 of 25 (88\%) patients treated with free vascularized fibular grafting (one experienced refracture), and all patients treated with both fibular grafting and Ilizarov fixation.

IM rodding is an alternative treatment option to achieve and maintain union, although the reported results are variable. Joseph and Mathew [24] reported 14 skeletally immature patients treated with IM rodding and double onlay autogenous bone grafting from the opposite tibia. The mean patient age was 4.5 years, the union rate was $86 \%$, the mean followup duration was 3 years, and the refracture rate was $21 \%$ (three of 14 ).

Johnston [23] presented a report of 23 patients treated with different techniques of IM rodding and grafting. The mean patient age was 2 years 4 months, the mean followup 
duration was 9 years, the primary union rate was $87 \%$, and $13 \%$ had persistent nonunion and bad outcomes. The author noted that two important factors for the best outcome for patients with CPT were perfect limb alignment and the use of IM rods to achieve union, prevent refracture, and maintain alignment.

Kim and Weinstein [27] presented a report of 11 patients with 12 tibiae with congenital pseudarthrosis treated with IM rodding and free bone grafting. The mean patient age at the time of the index operation was 2.5 years. Four of the 11 patients healed after the primary index operation. Two of the four experienced refracture; one healed with a long lower limb cast, and the other healed after the index operation was repeated. The other seven did not heal after the index operation. Four of them achieved healing after undergoing multiple surgical procedures (one required free vascularized fibular grafting, and three required repeated IM rodding and grafting; one of the three had nonunion, one needed Syme amputation, and one had a failed Sofield procedure). Healing could not be achieved in the other three patients (two underwent below-knee amputation, and one had persistent nonunion at the latest followup visit). Kim concluded that IM rodding provides more predictable results in cases of late-onset pseudarthrosis.

Dobbs et al. [9, 10] reported the long-term followup (mean followup duration, 14.2 years) of 21 patients with CPT (mean patient age, 5.1 years) treated with IM rodding and bone grafting. The primary union rate was $86 \%$ (18 patients), and three patients required additional bone grafting to achieve union. Twelve patients $(57 \%)$ experienced refracture, and five $(24 \%)$ required amputation.

Free vascularized fibular grafting had been described by several authors as a good option for acheiving union in patients with CPT, although it is associated with many drawbacks, including nonunion, refracture, and recurrent nonunion at one site of the graft end [11, 16, 25, 45]. Angular deformity of the affected tibia (valgus or anterior bowing) has been reported. The deformities usually are progressive and require further treatment $[15,25,45]$. Donor site morbidity, such as progressive ankle valgus with proximal migration of the distal fibula, is another problem associated with vascularized fibular grafting [15, 25, 45]. The tibiofibular synostosis can only delay but not prevent ankle valgus [15].

Weiland et al. [45] presented a report of 19 patients with a $95 \%$ union rate. Initial failure to achieve union occurred in 26\% (five of 19 patients), and those patients required secondary procedures to achieve union (four healed and one underwent amputation).

Gilbert [16] reported the long-term followup of 29 patients who had CPT treated with microvascular fibular grafting, all of whom had reached skeletal maturity. The union rate was $94 \%$ with a mean healing time of 6 months. The mean patient age at the time of the index operaion was 5.5 years, the refracture rate was $14 \%$, and the reccurence rate was $7 \%$. Donor site morbidity occurred in $24 \%$, tibial deformity (valgus and anterior bowing ) occurred in $24 \%$, progressive LLD occurred in $7 \%$, and no ampuation was recorded.

The EPOS study [26, 39] reported a healing rate of $61 \%$ (19 of 31 patients). Seven of the 19 healed patients required additional procedures, such as grafting, plating, or IM rodding. The remaining 12 healed after the primary treatment and did not require additional surgery. Three patients (10\%) required amputations, seven (23\%) had not healed, and five $(16 \%)$ experienced fracture of the transfered fibula. 
Toh et al. [43] reported seven cases of CPT treated with vascularized fibular graft, with a mean followup duration of 12.1 years. Casting or monolateral external fixation was used in the first cases; an Ilizarov fixator was used as a postopertative immobilization tool in one case. The author concluded that the best outcome can be acheived with combined vascularized fibular grafting and Ilizarov external fixation as a method of postopertaive fixation.

El-Gamal et al. [12] reported three cases of CPT treated with vascularized fibular grafting combined with Ilizarov fixation to distract the fibular graft to correct LLD with a single operation. They called it 'telescoping vascularized fibular graft'. The mean patient age was 9 years, and the mean followup duration was 2 years. Union was achieved in all cases. One patient experienced refracture, and another patient experienced ankle valgus of the affected site.

Amputation is an option in cases of CPT $[18,30]$. Its incidence varies from series to series. McCarthy [30] noted that foot condition, number of operations, and severity of LLD are the factors that determine the need for amputation.

Pharmacologic therapuetic solutions for CPT recently have become available: BMP-2, BMP-7 and bisphosphonate therapy (ZA) [20, 28, 40]. Lee et al. [28] reported five cases of CPT treated with BMP-7 combined with corticocancellous allograft and IM rodding combined with external fixation. The mean patient age was 6 years, and the mean followup duration was 14 months. The authors conluded that the use of recombinant human BMP-7 is not enough to overcome the poor healing environment associated with CPT. Little and colleagues [20,40] used bisphosphonate (ZA) for patients with CPT to control the activity of osteoclasts to promote union and prevent the bone graft from resorption.

Thabet, Paley, Kocoaglu et al [42] conducted a retrospective study of 20 patients with CPT who were treated with periosteal grafting and bone grafting combined with IM rodding of the tibia and fibula and circular external fixation by the senior authors between 1997 and 2006 at two centers. The mean age at the index operation was 4.2 years (age range, 1-11.3 years). Eleven patients (55\%) had neurofibromatosis, in seven patients $(35 \%)$ the condition was idiopathic, and two patients $(10 \%)$ had osteofibrous dysplasia. Twelve patients $(60 \%)$ had no previous surgery, and eight patients $(40 \%)$ had undergone at least one unsuccessful operation (range, 0-14). All patients had established pseudarthrosis. Union was achieved in all patients $(100 \%)$. The mean time spent in external fixation was 5.2 months (range, 3-12 months). Limb lengthening was achieved in 12 patients. The mean lengthening amount was $2.5 \mathrm{~cm}$ (range, $0-7 \mathrm{~cm}$ ); epiphysiodesis of the opposite side was performed in one patient.

Refracture occurred in eight patients: six experienced one refracture each, and two experienced two refractures each. Six of the eight patients with refracture had fibular pseudarthrosis. The mean time between the index operation and refracture was 2.3 years (range, 1-5.8 years), and the mean time between the index operation and second refracture was 4.7 years. The mean age at the index operation of patients who experienced refracture was 4 years (range, 1-7.3 years). The mean followup duration was 4.3 years (range, 2-10.7 years). All of the refractures were treated and all healed with surgery.

Most recently Paley studied 15 cases treated by the combined pharmacologic and surgical management method described above. The age range was from 1-10 years (mean 4 years). All patients united. There were no refractures. The average followup was 2 years (range 1-4). 
Based on these results there is reason to believe that combining BMP and bisphosphonate treatment in clinical practice is a useful adjunct as was shown in the animal model [40]. In a review of CPT, Johnston and Birch [22] advocated using BMP as an adjuvant treatment in all primary and recalcitrant cases. Despite optimism with the use of BMP, one must also consider theoretical risk of tumorgenesis because BMP stimulates the RAS pathway, which is also a tumor pathway. Patients with CPT have a propensity for both benign and malignant tumors. Although there has never been a report of such a complication, it should be discussed with patients since rhBMP is not FDA-approved for children or for CPT.

The Paley method of combined pharmacologic and surgical management is a shotgun approach to management of this potentially devastating problem. It optimizes the mechanical [33] and biologic environment for the CPT. It is impossible to identify which factor is more important for the healing of CPT since no control group or comparison study has been done. Since this is a rare disease and failure is devastating it is more important to have a successful method than to be certain which component of the treatment regimen is the most important to achieving successful union. As newer pharmacologic therapeutics and better understanding of the patho-etiology of this disease occur, the combined pharmacologic surgical technique will morph to include newer technologies and therapeutics. Meanwhile the combination treatment; hamartoma resection, periosteal grafting, bone grafting, internal rodding, external fixation, tibio-fibular cross union, BMP and bisphosphonate pharmacologic manipulation are the best current combination treatment for CPT.

\section{References}

[1] Blauth M, Harms D, Schmidt D, Blauth W. Light- and electron-microscopic studies in congenital pseudarthrosis. Arch Orthop Trauma Surg. 1984;103:269-277.

[2] Boero S, Catagni M, Donzelli O, Facchini R, Frediani PV. Congenital pseudarthrosis of the tibia associated with neurofibromatosis-1: treatment with Ilizarov's device. J Pediatr Orthop. 1997;17:675-684.

[3] Boyd HB. Pathology and natural history of congenital pseudarthrosis of the tibia. Clin Orthop Relat Res. 1982;166:5-13.

[4] Boyd HB, Sage FP. Congenital pseudarthrosis of the tibia. J Bone Joint Surg Am. 1958;40:1245-1270.

[5] Campanacci M, Zanoli S. Double tibiofibular synostosis (fibula pro tibia) for non-union and delayed union of the tibia: end-result review of one hundred seventy-one cases. J Bone Joint Surg Am. 1966;48:44-56.

[6] Charnley J. Congenital pseudarthrosis of the tibia treated by intramedullary nail. J Bone Joint Surg Am. 1956;38:283-290.

[7] Cho T-J, Seo JB, Lee HR, Chung CY, Choi IH. Biologic characteristics of fibrous hamartoma from congenital pseudarthrosis of the tibia associated with neurofibroumatosis type 1. J Bone Joint Surg Am 2008; 90 (12): 2735-44.

[8] Codivilla A. On the cure of the congenital pseudoarthrosis of the tibia by means of periosteal transplanation. J Bone Joint Surg Am. 1906;s2-4:163-169. 
[9] Dobbs MB, Rich MM, Gordon JE, Szymanski DA, Schoenecker PL. Use of an intramedullary rod for treatment of congenital pseudarthrosis of the tibia: a longterm followup study. J Bone Joint Surg Am. 2004;86:1186-1197.

[10] Dobbs MB, Rich MM, Gordon JE, Szymanski DA, Schoenecker PL. Use of an intramedullary rod for the treatment of congenital pseudarthrosis of the tibia: surgical technique. J Bone Joint Surg Am. 2005;87(Suppl 1):33-40.

[11] Dormans JP, Krajbich JI, Zuker R, Demuynk M. Congenital pseudarthrosis of the tibia: treatment with free vascularized fibular grafts. J Pediatr Orthop. 1990;10:623-628.

[12] El-Gammal TA, El-Sayed A, Kotb MM. Telescoping vascularized fibular graft: a new method for treatment of congenital tibial pseudarthrosis with severe shortening. $J$ Pediatr Orthop B. 2004;13:48-56.

[13] El-Rosasy MA, Paley D, Herzenberg JE. Congenital pseudarthrosis of the tibia. In: Rozbruch SR, Ilizarov S, eds. Limb Lengthening and Reconstruction Surgery. New York: Informa Healthcare; 2007:485-493.

[14] El-Rosasy MA, Paley D, Herzenberg JE. Ilizarov techniques for the management of congenital pseudarthrosis of the tibia (PhD Thesis). Tanta, Egypt: Tanta University Press; 2001.

[15] Fragnière B, Wicart P, Mascard E, Dubousset J. Prevention of ankle valgus after vascularized fibular grafts in children. Clin Orthop Relat Res. 2003;408:245-251.

[16] Gilbert A, Brockman R. Congenital pseudarthrosis of the tibia: long-term followup of 29 cases treated by microvascular bone transfer. Clin Orthop Relat Res. 1995;314:37-44.

[17] Grill F, Bollini G, Dungl P, Fixsen J, Hefti F, Ippolito E, Romanus B, Tudisco C, Wientroub S. Treatment approaches for congenital pseudarthrosis of tibia: results of the EPOS multicenter study: European Paediatric Orthopaedic Society (EPOS). J Pediatr Orthop B. 2000;9:75-89.

[18] Guille JT, Kumar SJ, Shah A. Spontaneous union of a congenital pseudarthrosis of the tibia after Syme amputation. Clin Orthop Relat Res. 1998;351:180-185.

[19] Hermanns-Sachweh B, Senderek J, Alfer J, Klosterhalfen B, Büttner R, Füzesi L, Weber M. Vascular changes in the periosteum of congenital pseudarthrosis of the tibia. Pathol Res Pract. 2005;201:305-312.

[20] Högler W, Yap F, Little D, Ambler G, McQuade M, Cowell CT. Short-term safety assessment in the use of intravenous zoledronic acid in children. J Pediatr. 2004;145:701-704.

[21] Ippolito E, Corsi A, Grill F, Wientroub S, Bianco P. Pathology of bone lesions associated with congenital pseudarthrosis of the leg. J Pediatr Orthop B. 2000;9:3-10.

[22] Jacobsen ST, Crawford AH, Millar EA, Steel HH. The Syme amputation in patients with congenital pseudarthrosis of the tibia. J Bone Joint Surg Am. 1983;65:533-537.

[23] Johnston CE II. Congenital pseudarthrosis of the tibia: results of technical variations in the Charnley-Williams procedure. J Bone Joint Surg Am. 2002;84:1799-1810.

[24] Joseph B, Mathew G. Management of congenital pseudarthrosis of the tibia by excision of the pseudarthrosis, onlay grafting, and intramedullary nailing. J Pediatr Orthop B. 2000;9:16-23.

[25] Kanaya F, Tsai TM, Harkess J. Vascularized bone grafts for congenital pseudarthrosis of the tibia. Microsurgery. 1996;17:459-469. 
[26] Keret D, Bollini G, Dungl P, Fixsen J, Grill F, Hefti F, Ippolito E, Romanus B, Tudisco C, Wientroub S. The fibula in congenital pseudoarthrosis of the tibia: the EPOS multicenter study: European Paediatric Orthopaedic Society (EPOS). J Pediatr Orthop B. 2000;9:69-74.

[27] Kim HW, Weinstein SL. Intramedullary fixation and bone grafting for congenital pseudarthrosis of the tibia. Clin Orthop Relat Res. 2002;405:250-257.

[28] Lee FY, Sinicropi SM, Lee FS, Vitale MG, Roye DP Jr, Choi IH. Treatment of congenital pseudarthrosis of the tibia with recombinant human bone morphogenetic protein-7 (rhBMP-7): a report of five cases. J Bone Joint Surg Am. 2006;88:627-633.

[29] Masserman RL, Peterson HA, Bianco AJ Jr. Congenital pseudarthrosis of the tibia: a review of the literature and 52 cases from the Mayo Clinic. Clin Orthop Relat Res. 1974;99:140-145.

[30] McCarthy RE. Amputation for congenital pseudarthrosis of the tibia: indications and techniques. Clin Orthop Relat Res. 1982;166:58-61.

[31] McElvenny RT. Congenital pseudarthrosis of the tibia: the findings in one case and a suggestion as to possible etiology and treatment. Q Bull Northwest Univ Med Sch. 1949;23:413-423.

[32] McFarland B. Pseudarthrosis of the tibia in childhood. I Bone Joint Surg Br. 1951;33:36-46.

[33] Morrissy RT. Congenital pseudarthrosis of the tibia: factors that affect results. Clin Orthop Relat Res. 1982;166:21-27.

[34] Ohnishi I, Sato W, Matsuyama J, Yajima H, Haga N, Kamegaya M, Minami A, Sato M, Yoshino S, Oki T, Nakamura K. Treatment of congenital pseudarthrosis of the tibia: a multicenter study in Japan. J Pediatr Orthop. 2005;25:219-224.

[35] Paley D, Catagni M, Argnani F, Prevot J, Bell D, Armstrong P. Treatment of congenital pseudoarthrosis of the tibia using the Ilizarov technique. Clin Orthop Relat Res. 1992;280:81-93.

[36] Paley D, Congenital Pseudarthrosis: Management. PanArabOrthopaediCongress Muscat, Oman Sept 11-14, 1995

[37] Paterson DC, Lewis GN, Cass CA. Treatment of congenital pseudarthrosis of the tibia with direct current stimulation. Clin Orthop Relat Res. 1980;148:129-135.

[38] Paterson DC, Simonis RB. Electrical stimulation in the treatment of congenital pseudarthrosis of the tibia. J Bone Joint Surg Br. 1985;67:454-462.

[39] Romanus B, Bollini G, Dungl P, Fixsen J, Grill F, Hefti F, Ippolito E, Tudisco C, Wientroub S. Free vascular fibular transfer in congenital pseudoarthrosis of the tibia: results of the EPOS multicenter study: European Paediatric Orthopaedic Society (EPOS). J Pediatr Orthop B. 2000;9:90-93.

[40] Schindeler A, Ramachandran M, Godfrey C, Morse A, McDonald M, Mikulec K, Little DG. Modeling bone morphogenetic protein and bisphosphonate combination therapy in wild-type and Nf1 haploinsufficient mice. J Orthop Res. 2008;26:65-74.

[41] Sofield HA. Congenital pseudarthrosis of the tibia. Clin Orthop Relat Res. 1971;76:33-42.

[42] Thabet AM, Paley D, Kocaoglu M, Eralp L, Herzenberg JE, Ergin ON. Periosteal grafting for congenital pseudarthrosis of the tibia: a preliminary report. Clin Orthop Relat Res. 2008;466:2981-94. Epub 2008 Oct 25. 
[43] Toh S, Harata S, Tsubo K, Inoue S, Narita S. Combining free vascularized fibula graft and the Ilizarov external fixator: recent approaches to congenital pseudarthrosis of the tibia. J Reconstr Microsurg. 2001;17:497-508.

[44] Weber M., Congenital pseudarthrosis of the tibia redefined: congenital crural segemental dysplasia. In: Rozbruch SR, Ilizarov S, eds. Limb Lengthening and Reconstruction Surgery. New York: Informa Healthcare; 2007:495-509.

[45] Weiland AJ, Weiss AP, Moore JR, Tolo VT. Vascularized fibular grafts in the treatment of congenital pseudarthrosis of the tibia. J Bone Joint Surg Am. 1990;72:654-662. 


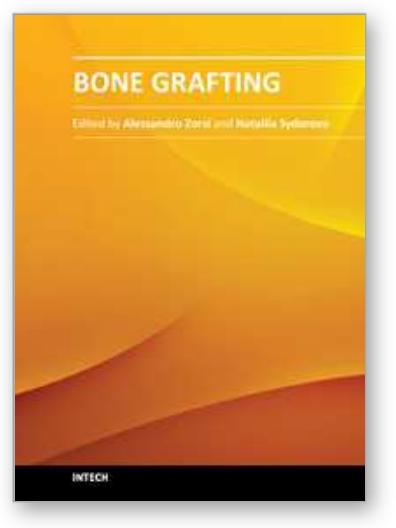

\author{
Bone Grafting \\ Edited by Dr Alessandro Zorzi
}

ISBN 978-953-51-0324-0

Hard cover, 214 pages

Publisher InTech

Published online 21, March, 2012

Published in print edition March, 2012

Bone grafting is the surgical procedure in which new bone (bone graft) or a replacement material (graft substitute), is placed into bone fractures or bone defects to aid in healing. Bone grafting is in the field of interest of many surgical specialties, such as: orthopedics, neurosurgery, dentistry, plastic surgery, head and neck surgery, otolaryngology and others. In common, all these specialties have to handle problems concerning the lack of bone tissue or impaired fracture healing. There is a myriad of surgical techniques nowadays involving some kind of bone graft or bone graft substitute. This book gathers authors from different continents, with different points of view and different experiences with bone grafting. Leading researchers of Asia, America and Europe have contributed as authors. In this book, the reader can find chapters from the ones on basic principles, devoted to students, to the ones on research results and description of new techniques, experts will find very beneficial.

\title{
How to reference
}

In order to correctly reference this scholarly work, feel free to copy and paste the following:

Dror Paley (2012). Congenital Pseudarthrosis of the Tibia: Combined Pharmacologic and Surgical Treatment Using Biphosphonate Intravenous Infusion and Bone Morphogenic Protein with Periosteal and Cancellous Autogenous Bone Grafting, Tibio-Fibular Cross Union, Intramedullary, Bone Grafting, Dr Alessandro Zorzi (Ed.), ISBN: 978-953-51-0324-0, InTech, Available from: http://www.intechopen.com/books/bonegrafting/treatment-of-congenital-pseudarthrosis-with-periosteal-and-cancellous-bone-grafting-

\section{INTECH}

open science | open minds

\section{InTech Europe}

University Campus STeP Ri

Slavka Krautzeka 83/A

51000 Rijeka, Croatia

Phone: +385 (51) 770447

Fax: +385 (51) 686166

www.intechopen.com

\section{InTech China}

Unit 405, Office Block, Hotel Equatorial Shanghai

No.65, Yan An Road (West), Shanghai, 200040, China

中国上海市延安西路65号上海国际贵都大饭店办公楼405单元

Phone: +86-21-62489820

Fax: $+86-21-62489821$ 
(C) 2012 The Author(s). Licensee IntechOpen. This is an open access article distributed under the terms of the Creative Commons Attribution 3.0 License, which permits unrestricted use, distribution, and reproduction in any medium, provided the original work is properly cited. 